\title{
Reflexiones acerca de una acción colectiva juvenil: La "Marcha de la Gorra" y su multiplicidad
}

\author{
Thoughts about a youth collective action: \\ The "Marcha de la Gorra" and its multiplicity
}

Andrea Bonvillani ${ }^{1}$ abonvillani@gmail.com

Melania Agustina Chaboux ${ }^{2}$

cxagustina@gmail.com

\begin{abstract}
Resumen
Desde 2007, la "Marcha de la Gorra" irrumpe en el centro de la ciudad de Córdoba (Argentina) demandando la transformación de la política de seguridad de la Provincia, por considerarla violatoria de los derechos humanos de los jóvenes de sectores populares. El enfoque metodológico de la investigación que originó este artículo se enmarca en la "Etnografía de eventos" (en el sentido propuesto por la antropóloga Borges). Nuestro propósito es analizar la Marcha en su diversidad y complejidad, evitando caer en cualquier tipo de esencialismo o pretensión unificadora.

Las líneas de sentido que permiten mostrar la cualidad de multiplicidad como clave analítica de la Marcha son varias. No obstante, en este artículo focalizaremos en la compleja diversidad de demandas y actores que se articulan en esta acción colectiva juvenil. Al mismo tiempo proponemos, a manera de hipótesis, una lectura sobre el impacto que esta multiplicidad tiene respecto de su potencialidad política.
\end{abstract}

\section{Palabras clave}

Acción colectiva, Marcha de la Gorra, jóvenes, multiplicidad, etnografía de eventos

Forma sugerida de citar: Bonvillani, Andrea \& Chaboux, Melania Agustina (2016). Reflexiones acerca de una acción colectiva juvenil: La "Marcha de la Gorra" y su multiplicidad. Universitas, XIV(1), pp. 91-118.

1 Doctorado y Posdoctorado en Psicología por la Universidad Nacional de Córdoba Argentina). Ex Becaria de Doctorado y Postdoctorado CONICET. Profesora e investigadora de la mencionada Universidad. Directora de distintos proyectos de Investigación a nivel local e internacional en el cruce de temáticas: juventudes-política-grupalidad, entre los que se destaca su participación de varios años en el Grupo de Trabajo del Consejo Latinoamericano de Ciencias Sociales (CLACSO) "Juventudes, Infancias: Instituciones Sociales, Políticas y Culturas en América Latina”. Directora del Colectivo Investigador "Marcha de la Gorra".

2 Licenciada en Ciencia Política por la Universidad Nacional de Río Cuarto (Argentina). Doctoranda en Administración y Política Pública en la Universidad Nacional de Córdoba. Becaria doctoral de CONICET. Actualmente forma parte del Colectivo Investigador "Marcha de la Gorra", dirigido por Andrea Bonvillani. 


\begin{abstract}
Since 2007, the "Marcha de la Gorra" bursts into Cordoba city center (Argentina) demanding the transformation of the provincial security policy, as it injures the popular sector young's human rights. This paper submits some aspects of a research in progress, its methodological approach enrolls in an "Ethnography of events" (according to the sense proposed by the anthropologist Borges). Our purpose is to analyze this march in its diversity and complexity, avoiding any kind of essentialism or unifying claim.

There are several aspects that show that multiplicity is a key to analyze the protest. However, this article will focus on the complex diversity of demands and actors that are articulated in this youthful collective action. At the same time we propose, as a hypothesis, a reading on the impact that this multiplicity has regarding its political potential.
\end{abstract}

\title{
Keywords
}

Collective action, Marcha de la Gorra, young people, multiplicity, ethnography of events.

\section{Presentación e inscripción en un campo problemático}

Desde el año 2007, cada 20 de noviembre ${ }^{3}$ miles de personas, en su mayoría jóvenes, toman las calles del centro de la ciudad de Córdoba (Argentina) para demandar, en términos generales, la transformación de la política de seguridad provincial que, como argumentaremos más adelante, resulta violatoria de los derechos humanos de aquellos grupos sociales más vulnerables.

Conceptualmente, la "Marcha de la Gorra" (en adelante, la Marcha) se encuadra dentro de las prácticas de acción colectiva contenciosa (Tarrow, 1997) $)^{4}$ una expresión callejera, polemizante y pública que, a través de un amplio y nutrido repertorio de actividades y protagonizada por diversos ac-

3 En esta fecha se conmemora el día en que la Asamblea General de las Naciones Unidas aprobó la Declaración de los Derechos del Niño en 1959 y la Convención sobre los Derechos del Niño en 1989.

4 Tarrow (1997) explica que una acción colectiva "se convierte en contenciosa cuando es utilizada por gente que carece de acceso regular a las instituciones, que actúa en nombre de reivindicaciones nuevas o no aceptadas y que se conduce de un modo que constituye una amenaza fundamental para otros" (p. 19). 
tores sociales, enuncia y visibiliza en la escena política un conjunto de demandas y reivindicaciones.

Considerando el reclamo central que da sentido político a la Marcha, inscribiremos su estudio en un campo latinoamericano de indagación emergente en los últimos años, que se deriva de la creciente criminalización de las juventudes populares en la región. El mismo encuentra su referencia más destacada en el concepto de "juvenicidio", es decir el sistemático asesinato de jóvenes -generalmente a manos del Estado- y que resulta el corolario de los "procesos de precarización económica y social, la estigmatización y construcción de grupos o identidades juveniles desacreditadas" (Valenzuela Arce, 2015a, p.15). De esta manera, la Marcha se constituye en una práctica colectiva de resistencia frente al prejuicio generalizado sobre la peligrosidad juvenil, creado performativamente por el Estado y reforzado por los medios masivos de comunicación, que instituyen cotidianamente un régimen de sentido por el que se considera una obviedad la equivalencia simbólica "joven pobre=peligroso" (Bonvillani, 2015a).

Esta construcción interesada de determinados grupos sociales juveniles como portadores de una disposición hacia la violencia $\mathrm{y}$, por ende, como sus principales responsables, ha sido reportada desde hace más de una década respecto del contexto latinoamericano (Reguillo, 2003) y argentino (Chaves, 2005; Núñez, 2006). Decimos "interesada" en la medida en que se constituye en una solución de compromiso frente a la creciente demanda de seguridad de la población, ya que ubicando a los jóvenes pobres como los operadores del delito urbano se legitima acciones cotidianas de hostigamiento, humillación y castigo físico que incluso pueden llegar a su muerte, pero que tranquilizan los ánimos sociales respecto de una problemática social altamente sensible. Estas situaciones que a diario viven las juventudes populares en sus barrios y en los espacios céntricos de las ciudades argentinas, muestran los que algunos autores han designado como "policiamiento" (Kessler y Dimarco, 2013), ya que tienen como brazo ejecutor a las fuerzas policiales, que se constituyen en los antagonistas principales de los jóvenes en el territorio (Vázquez y Vommaro, 2009).

Desde su modelización teórica, las acciones colectivas contenciosas se definen como espacios de convergencia de una pluralidad de sujetos y grupos, es decir que la diversidad de intereses, trayectorias y modalidades de participación forma parte de las tematizaciones de su campo de estudio. Desde ese marco, se puede enunciar un primer propósito de este traba- 
jo, esto es: dotar de contenido específico esta afirmación genérica para dar cuenta de la multiplicidad de actores juveniles que agencian la Marcha de la Gorra, y de la forma de tramitar sus diferencias en la arena política en la que inscriben su práctica.

En tal sentido, un primer supuesto desde el que partimos es que toda vez que se pronuncia el sintagma "la Marcha", se corre el riesgo de suponer la existencia de una cosa en sí, una especie de plenitud homogénea o entidad sustancial, sin rugosidades, sin aristas, sin matices. En consecuencia, proponemos analizar esta acción juvenil de protesta en su diversidad y complejidad, evitando caer en cualquier tipo de esencialismo o pretensión unificadora. La multiplicidad de la que pretendemos dar cuenta será entendida aquí desde una aproximación a la perspectiva de Deleuze y Guattari (1997), es decir como un principio de comprensión que escapa a la idea de que existiera una unidad que, de antemano y de modo esencial, pudiera definir un objeto de investigación, por ejemplo.

Las líneas de sentido que permiten mostrar la cualidad de multiplicidad como clave analítica de la Marcha son varias ${ }^{5}$. No obstante, en este artículo focalizaremos en la compleja diversidad de demandas y actores que se articulan en esta acción colectiva juvenil. Al mismo tiempo proponemos, a manera de hipótesis, una lectura sobre el impacto que esta multiplicidad tiene respecto de la potencialidad política de la Marcha.

\section{Acerca del Código de Faltas}

El principal reclamo que articula la Marcha es la derogación del "Código de Faltas"6 (en adelante, el Código), una normativa de orden provincial

5 Por ejemplo, la que remite a las intervenciones gráficas, teatrales, audiovisuales que por su cantidad y diversidad, nos permiten caracterizar a la Marcha dentro de lo que Reguillo (2007) denomina "carnavalización”, como rasgo de la protesta juvenil en el momento actual. Para profundizar al respecto, véase Bonvillani (2015b).

6 El mismo fue sancionado originalmente en el año 1994, pero la versión a la que se refiere este artículo es la revisada y ordenada en el año 2007. Cabe señalar que esta norma mantuvo su vigencia hasta el 1 de abril de 2016, puesto que en diciembre de 2015 se aprobó el nuevo Código provincial de Convivencia Ciudadana, que lo reemplazó. Los avances que las autoridades provinciales le atribuyen, no son considerados tales por distintos analistas locales, puesto que se mantienen un conjunto de arbitrariedades que detallaremos a continuación. Fuente: "Un código que sigue en falta", artículo publicado por Mariana Lerchundi. Revista El Sur, 6/12/15. Disponible en http://revistaelsur.com.ar/ nota/142/Un-Codigo-que-sigue-en-falta. 
cuyo propósito formal es regular las contravenciones ${ }^{7}$ en la vía pública, es decir aquellas faltas menores que no son alcanzadas por el derecho penal. El Código constituye "una expresión de política pública de seguridad del Estado de la Provincia de Córdoba” (Bonvillani, 2015, p. 86) ${ }^{8}$. En este marco, se tomaron diferentes medidas que profundizaron una visión punitiva sobre la seguridad, cada vez más alejada de las garantías constitucionales y reducida a la mera protección de bienes privados (Plaza Schaefer y Morales, 2013). Se trata de un conjunto articulado de acciones tales como: el aumento desproporcionado del personal policial y del equipamiento correspondiente, el incremento de los controles en la vía pública, la construcción de nuevos establecimientos penitenciarios, etc. Se configura así un "Estado Penal" (Wacquant, 2010), que procura el gobierno de la inseguridad social a través de la criminalización de la pobreza9 .

El Código viola la Constitución Provincial, Nacional y los pactos internacionales de Derechos Humanos a los que Argentina adhiere, dado que lesiona diversos principios y derechos allí contemplados, tales como el principio de legalidad, el de inocencia, el de razonabilidad, el derecho de defensa

7 Acciones que no son en sí un delito pero que potencialmente podrían llegar a serlo. Las conductas que el Código incluye en esta categoría se reflejan en los artículos número: 45 (prostitución molesta o escandalosa), 52 (escándalos públicos), 61 incorporado por ley 9.109 (consumo de bebidas alcohólicas en vía pública o plazas), 62 (ebriedad o borrachera escandalosa), 79 (negativa u omisión a identificarse), 83 (patotas), 86 (portación ilegal de armas), 90 (uso indebido de teléfonos), 97 (posesión injustificada de llaves alteradas o de ganzúas), 98 (merodeo), y 99 (reuniones públicas tumultuarias), entre otros.

8 La Provincia de Córdoba, es la segunda en importancia en Argentina, después de Buenos Aires. está ubicada en el centro del país y tiene 3308876 habitantes, de acuerdo al último Censo Nacional de Población, Hogares y Viviendas realizado en 2010. E1 40\% de su población vive en la capital provincial, ciudad homónima, con 1329604 de habitantes, convirtiéndola en la segunda aglomeración urbana del país después del Gran Buenos Aires. Desde el año 1999 la Provincia es gobernada por el Partido Justicialista: tres gestiones de José Manuel de la Sota se han intercalado con dos mandatos de Juan Schiaretti, quien actualmente se encuentra en funciones. Durante más de 16 años, esta administración ha efectivizado un conjunto de medidas que encarnan una concepción represiva sobre los modos de "aseguramiento público", que incluyen no solo la mantención de normativas que violan sistemáticamente los derechos humanos, sino prácticas cotidianas vinculadas a la violencia estatal.

9 Siguiendo al mencionado autor, entendemos que esta norma constituye un instrumento inspirado en la denominada "doctrina de la tolerancia cero" (Wacquant, 2004). Esta concepción asume la premisa de que existiría una correspondencia entre los actos delictivos y algunas conductas o acciones entendidas como "incivilidades" (personas en situación de calle, trabajadoras sexuales, adictos, etc.), debido a que estos estarían atentando contra un orden social hipervalorado. Según esta doctrina, la presencia de estas formas de vida en el espacio público tendría que ser eliminada, ya que serían los elementos precursores de la criminalidad. Es por esto que se consideraría necesario el accionar de forma preventiva sobre contravenciones de bajo impacto criminal para evitar hechos más graves. 
en juicio, el de acceso a la justicia, a circular, a trabajar. Asimismo, la vaguedad y ambigüedad en la definición de las conductas sancionadas como contravenciones, sumado a la posibilidad de actuar de oficio ${ }^{10}$ ( $\sin$ orden judicial de por medio) y efectuar detenciones preventivas ${ }^{11}$-es decir, sin la comisión del hecho, sólo fundamentadas en la sospecha del oficial-, por parte de los agentes policiales en la vía pública, posibilitaron un crecimiento de las aprehensiones en un 700\%, entre 2005 y 2011; de las cuales un 70\% tuvieron como principal blanco a los jóvenes, fundamentalmente, varones y pobres (Brocca et al., 2015).

Este Código hace pie en un imaginario social instituido a partir del cual el joven de sector popular es concebido, a priori, como un sujeto esencialmente peligroso. Entre las consecuencias prácticas y políticas de esta construcción simbólica, se ubican "las detenciones masivas por Código de Faltas a jóvenes cordobeses por su condición de pobre, mestizo, barrial y joven" (Crisáfulli y León Barreto, 2015, p. 202). Además, la aplicación del Código implica en la práctica una profunda restricción para los jóvenes ${ }^{12}$ de sectores populares cordobeses a acceder y disfrutar del espacio céntrico de la ciudad, ya que la persecución policial y las detenciones arbitrarias lo tienen, generalmente, como escenario. Esto se traduce en un claro límite en el disfrute del espacio público en varios sentidos, entre el que se destaca el acceso a oportunidades de empleo puesto que las mismas se concentran ahí. Es así como esta normativa construye performativamente ${ }^{13}$ sujetos deseados y no deseados, en un ejercicio de distribución de los cuerpos aptos para habitar el centro de la ciudad.

Es esta construcción y comprensión de la peligrosidad de los jóvenes por parte del dispositivo de seguridad de la Provincia de Córdoba la que es recusada por la Marcha de la Gorra. Por una tarde, los marchantes se apropian del centro de la ciudad, le imprimen un sentido singular, lo resemantizan. Durante la Marcha, jóvenes de los barrios populares cordobeses,

10 Art. 115 del Código.

11 Art. 123 del Código.

12 La decisión de utilizar el género gramatical masculino no supone un posicionamiento sexista ni una subordinación del género femenino, sino que pretende hacer más fluida la escritura y la lectura.

13 Si bien la complejidad conceptual de esta categoría excede los límites de este artículo, lo utilizaremos para aludir a una dimensión presente en algunos enunciados que, además de constatar una realidad, también son capaces de producirla. Es decir, se trata de la posibilidad de hacer cosas con palabras, adscribiendo a la tradición teórica de Austin (1982). 
agrupaciones estudiantiles, partidos políticos, y organizaciones de diversa índole, salen a la calle, se adueñan de un espacio de la ciudad que habitualmente se les niega, para visibilizar su lucha política: formar parte de la sociedad sin ser discriminados ni criminalizados. Es así como la Marcha se constituye en un fenómeno sociopolítico que disputa los sentidos hegemónicos que en Córdoba se construyen sobre las juventudes, sobre los usos de la ciudad y sobre la noción de seguridad.

\section{Algunas precisiones metodológicas}

Este artículo focaliza sobre algunas dimensiones analíticas emergentes del desarrollo de una investigación ${ }^{14}$, que tiene como propósito explorar y reconstruir las configuraciones de subjetividad política que los jóvenes cordobeses construyen a partir de su participación en la Marcha como acción colectiva. Para ello hemos optado por las herramientas metodológicas que proponen la perspectiva cualitativa en general y la investigación etnográfica en particular.

Buscando re-construir en profundidad la riqueza y complejidad del evento-Marcha, la investigación que motiva este artículo se encuadra, metodológicamente, en lo que hemos denominado una "Etnografía colectiva de eventos" (Bonvillani, 2013), inspirándonos en la propuesta de la antropóloga brasilera Borges (2004), pero intentando enriquecerla con algunas decisiones que a continuación detallaremos. Una primera particularidad de nuestro diseño, ha sido la realización de un trabajo colectivo que supuso la participación coordinada de varios investigadores, los cuales han aportado cooperativamente sus registros de trabajo de campo.

Se trata de una apuesta etnográfica atípica, en la medida en que las condiciones del evento estudiado son la fugacidad (el encuentro se desarrolla en un día determinado, con pocas horas de duración) y la inestabilidad (la Marcha es movimiento, tránsito por el espacio público urbano), desafiando la témporo-espacialidad estable, propia de la etnografía tradicional. En la práctica, nuestra experiencia de encuentro con una manifestación de la magnitud numérica y diversidad en los repertorios de acción que la integran, ha exigi-

14 Denominada "La 'Marcha de la Gorra' como experiencia de subjetivación política de jóvenes de Córdoba (Argentina)”. Dirigida por Andrea Bonvillani, Subsidio de la Secretaría de Ciencia y Tecnología de la Universidad Nacional de Córdoba. Periodo: 2014-2015, categoría A. Código 05/P168. 
do un esfuerzo inquieto y riguroso, para procurar dar cuenta de la multiplicidad de sentidos que en este escenario hemos podido reconstruir. En consecuencia, hemos desplegado algo así como un "mosaiquismo metodológico" (Bonvillani, 2015) que, articulando distintas técnicas de construcción de datos, intenta dar cuenta de la experiencia multivariada de vivir la Marcha

Si bien se recopiló material antes y después del evento, el trabajo de campo más intenso se realizó el día de la Marcha, desde las horas previas a la concentración, hasta los momentos posteriores a su finalización. Se combinaron distintas formas de estar ahí, en el lugar-evento, tales como observaciones etnográficas, crónicas en primera persona de las intervenciones desplegadas a partir de disciplinas artísticas como el teatro y la murga ${ }^{15}$, prestando especial atención al registro audiovisual. Esto nos permitió construir un nutrido corpus etnográfico a partir de la experiencia de acompañar la Marcha desde su sexta edición, en el 2012. Forma parte de dicho corpus el siguiente material:

a. Registros de observaciones de la Marcha; especialmente crónicas de lo que denominamos "intervenciones en Marcha", y que clasificamos en:

- gráficas (grafitis, stencils, banderas, remeras, cuerpos pintados, etc.)

- $\quad$ escénicas (teatro, coro, murgas, etc.)

- discurso público de los organizadores;

b. Registros de las reuniones previas a la realización de la Marcha ${ }^{16}$.

c. Conversaciones-en-Marcha (Bonvillani, 2015) ${ }^{17}$.

d. Entrevistas en profundidad post-Marcha con manifestantes, policías y "observadores" (Fillieule y Tartakowski, 2015).

e. Documentos elaborados por las organizaciones convocantes y participantes para difundir la Marcha, sus actividades y propuestas.

15 La murga es una forma de expresión artística rioplatense que combina música popular con teatralidad, utilizando instrumentos de percusión y coros, así como movimientos corporales particulares y altamente rítmicos. Se llama murga al género, como a la compañía que lo practica.

16 Agradecemos especialmente al Colectivo de Jóvenes por Nuestros Derechos por ceder estos registros a los fines del análisis.

17 Diálogos informales, generalmente breves y situados, en los que se intercambian impresiones acerca de lo que se está percibiendo-sintiendo-haciendo al calor de la movilización, con los denominados “marchantes". Vale la pena señalar que estas conversaciones están atravesados por los climas subjetivos y colectivos propios de una movilización de protesta, tales como intentar pensar sobre lo que se hace contemporáneamente a la propia acción, acompasando esta tentativa reflexiva con el caminar, saltar, gritar, cantar, bailar, etc. 
f. Materiales legales o institucionales, tales como textos de normas o la versión taquigráfica de la Audiencia pública de la Comisión especial para el estudio, análisis, modernización y reforma del Código de Faltas.

g. Artículos publicados en periódicos locales, antes, durante y después de la Marcha.

h. Registro fotográfico y fílmico.

i. Conversaciones grupales entre el Colectivo de Jóvenes por Nuestros Derechos (en adelante, el Colectivo), principal referente de la Marcha y el equipo de investigación.

El presente artículo recupera parte de los análisis producidos a partir de la aplicación de algunas de estas técnicas ${ }^{18}$. Los registros corresponden a las últimas cuatro Marchas realizadas entre los años 2012 y 2015, es decir de la Sexta a la Novena edición.

\section{La Marcha de la Gorra: Aspectos organizativos y dimensiones simbólicas de la lucha}

En un plano descriptivo inicial, es posible advertir la presencia de una variedad de organizaciones sociales, de derechos humanos, político-partidarias, sindicales, culturales, académicas, estudiantiles, territoriales, etc. ${ }^{19}$, mayoritariamente de carácter juvenil ${ }^{20}$ que nutre la manifestación. También forman parte de la misma los familiares de víctimas de persecución policial,

18 En cada caso se señalará la técnica de la que es producto el fragmento citado, con indicación de la fecha correspondiente de producción y nombre ficticio del hablante, a los fines de resguardar su identidad. En esta forma de citación, existirá una excepción cuando se trate de los nombres de los integrantes del equipo investigador que serán los reales.

19 En un relevamiento cartográfico realizado por este equipo de investigación, se encontraron, en 2014, aproximadamente cien agrupaciones coorganizando la Marcha (Chaboux y Monsó, 2015). En virtud de ello, el espacio de organización de esta acción colectiva es tan amplio y heterogéneo que se convierte en una construcción política excesivamente compleja y sofisticada, que, por supuesto, no está exenta de conflictos, tensiones y disputas de poder.

20 Con lo "juvenil" queremos designar una dimensión analítica que desborda el criterio de la edad como demarcador de límites vinculados con el desarrollo evolutivo, lo que hace necesario el análisis de la diversidad de prácticas, comportamientos y universos simbólicos que ella puede incluir, de acuerdo con factores de clase, género, etnia, etc. Justamente la referencia a aspectos culturales que configuran un determinado estilo de vida juvenil popular, es clave para comprender los modos de adscripción a partir de los cuales algunos actores se sienten interpelados por esta acción de protesta. 
jóvenes de los barrios, profesionales, artistas, familias, en fin: un grupo muy heterogéneo de ciudadanos que no se movilizan bajo ninguna bandera o atributo que pudiera hacer pensar en afiliación de ningún tipo, al que hemos denominado "auto-convocado".

Por otra parte, la magnitud numérica de la Marcha ha ido creciendo desde sus orígenes en $2007^{21}$, para tornarse en la actualidad en un evento multitudinario, lo cual explica que su organización sea una necesidad. De hecho, podríamos decir que la Marcha comienza mucho antes del encuentro de los manifestantes en el centro de la ciudad, confluyendo desde sus barrios. Se empieza a marchar en las reuniones organizativas semanales, que comienzan varios meses antes del 20 de noviembre de cada año, y se realizan en un local céntrico perteneciente a una Asociación civil de la ciudad de Córdoba.

A cargo de la convocatoria y organización general se encuentra el Colectivo de Jóvenes por Nuestros Derechos, en su calidad de fundador y referente de la Marcha. Año tras año, se conforma una "Mesa organizadora", integrada por una diversidad de agrupaciones sociales, políticas y culturales, que convergen de manera abierta, sin ningún tipo de restricción material. El modo de funcionamiento supone la división en "Comisiones de trabajo", que se ocupan de distintos aspectos, tales como: Documento público ${ }^{22}, \mathrm{Ar}-$ tística, Seguridad, Comunicación, Finanzas y Logística. Desde el año 2014, comenzó a funcionar la llamada "Comisión interprovincial", que tuvo como propósito articular la experiencia de la Marcha de la Gorra de Córdoba, con las iniciativas de otras localidades de la Provincia (tales como Río Cuarto, Villa María, etc.). Las decisiones que se toman en este espacio van desde a quién se contrata para que provea el sonido y la iluminación del evento, hasta el contenido político del mencionado Documento, pasando por las distintas intervenciones que se desarrollarán en la calle, los aspectos que hacen a la seguridad de los manifestantes, y los modos de difundir la propuesta.

21 De acuerdo a los organizadores, en la primera edición marcharon aproximadamente 300 personas. Mientras que en 2012 se contaron más de 10.000 marchantes y más de 15000 en 2013. Las últimas dos ediciones de la Marcha (2014 y 2015) pasaron a convocar a alrededor de 20000 personas (Fuentes: Diario cba24n, 21/11/2012: "Masiva marcha de la gorra contra el código de faltas"; Diario cba24n, 20/11/2013: "Masiva marcha de la gorra contra el Código de faltas"; Sitio Web oficial de la Marcha de la Gorra, 24/11/2014: "20 mil gorras marcharon" y Sitio Web oficial de la Marcha de la Gorra, 19/11/2015: "Y la hicimos de frente mar")

22 Se lee en el escenario central como cierre de cada Marcha. Opera simbólicamente como manifiesto del espíritu que la movilización adquiere, en la coyuntura en la que se realiza. Para ampliar sobre el particular, véase Lescano (2015). 
En términos generales, esta forma de funcionamiento remite a una lógica "asamblearia", que supone una modalidad colectiva en la toma de decisiones, a partir de la discusión que se desarrolla en este espacio, en dos momentos diferenciados. En cada encuentro, se destina una fracción de tiempo al debate y propuestas específicas de los tópicos de cada Comisión, que luego se ponen en común en la Reunión Plenaria o General, donde finalmente se resuelve. La integración a las Comisiones es voluntaria, y cuenta con uno o dos coordinadores, que son miembros del Colectivo, quienes también coordinan la puesta en común.

En este punto, resulta oportuno dar tratamiento a una dimensión de la Marcha que queda enunciada en su propio nombre: ¿por qué "Marcha de la Gorra"?

Desde su momento fundacional en el año 2007, el reclamo que aparece en la voz de aquellos protagonistas de esta acción colectiva excede lo que podría pensarse como una simple disposición vengativa hacia las fuerzas del orden. La lectura política del colectivo que activa año tras año esta convocatoria inscribe la problemática que padecen los jóvenes en un registro de persecución por pertenecer a un grupo social que tiene una determinada cultura: "Nos detienen por la cultura" fue la consigna ${ }^{23}$ de la quinta edición de la Marcha, realizada en 2011.

En otro lugar (Bonvillani, 2015), hemos formulado la relación entre el corpus jurídico "Código de faltas provincial" y determinadas creencias hegemónicas cristalizadas en imaginarios sociales locales, que operarían en la base ideológica del mismo. Esta ligazón permitiría dar cuenta tanto de los orígenes de la inclinación a perseguir a determinados grupos sociales a partir de la vigencia de relaciones de desigualdad, como del uso de canales legales para su concreción.

Quizá la violación más flagrante a los derechos humanos contenida en el Código sea la aplicación de la figura jurídica del "Merodeo", que permite detener a aquellos que "permanecieran en las inmediaciones de (edificios o vehículos) en actitud sospechosa, sin una razón atendible, según las circunstancias del caso, o provocando intranquilidad entre sus propietarios"

23 Siempre dentro del campo de sentido que articula la demanda, cada edición de la Marcha pone énfasis en un aspecto particular, que muchas veces tematiza alguna situación local emergente y que se resume en la consigna de la Marcha, que varía año a año. La consigna, entonces, es la síntesis del sentir particular de la Marcha ese año, aquello que formula expresamente el motivo por el que se protesta. Consecuentemente, en la práctica, opera como un lema que le da identidad a cada edición de la Marcha, estando presente en todas las expresiones gráficas vinculadas a ella. 
(Artículo 98 del Código). ¿Cómo se define una actitud sospechosa? Al no estipular la norma ningún criterio objetivo que podría constituir una razón fundamentada para la detención, su justificación se apoya en la estimación prejuiciosa y discrecional del policía, a partir de la cual, como lo expresamos más arriba, establece relaciones de causalidad entre determinados atributos fisonómicos (color de piel) y de apariencia física (formas de vestirse, de caminar, de hablar) y la condición estable de la peligrosidad, que generalmente recae sobre los jóvenes varones de sectores populares. A su vez, desde esta perspectiva, la posesión de estos rasgos se asocia a una determinada pertenencia social y cultural, a la que se le otorgan atributos morales negativos, que justificarían una especie de sospecha omnipresente.

Los jóvenes de sectores populares de Córdoba, han acuñado la expresión "portación de rostro" 24 , para designar este enlace discriminatorio entre características raciales particulares y apariencia física y peligrosidad, metáfora que resignifica la canónica "portación de antecedentes", como criterio de sospecha en relación a la producción de un delito. Estas construcciones discursivas remiten desde las tendencias críticas de la Criminología, al denominado "derecho penal de autor" (Sabsay, 2011), el cual descansa no en la producción efectiva de un hecho, sino justamente en las características fisonómicas, de personalidad o de procedencia de aquel que es definido de antemano como culpable.

La gorra es uno de los componentes que hacen a una forma de presentación en la vida cotidiana de los jóvenes de sectores populares cordobeses: una especie de símbolo de reconocimiento que los identifica endogrupalmente, pero también frente a la mirada de los otros (policías) de modo diferencial, condensando el universo de estigmatizaciones que los ubica como culpables a priori. En consecuencia, la gorra es a la vez indicador de procedencia socio-cultural y portación que los arroja a la persecución. Pero tam-

24 Quizá sea el sintagma más recurrente para nominar la vivencia de persecución que somete a los jóvenes en la experiencia social cordobesa. De este modo lo recoge uno de los padres fundadores de la música tradicional local como es el cuarteto. Carlos "La "Mona" Jiménez, ha titulado una de sus canciones más reconocidas de este modo, diciendo: Detenido... /a mi casa voy, detenido... /yo vengo de estudiar / Detenido... /escúcheme oficial / ¿por qué motivo me quiere arrestar? /si no hice nada mal. /Por portación de rostro... Por portación de rostro... /Por portación de rostro... Por portación de rostro... /Yo no tengo la culpa /de tener este rostro, /porque es una obra de mamá y papá, /piel oscura por fuera pero blanco por dentro, /soy muy pobre y humilde/vivo con dignidad/de la casa al trabajo /del trabajo al colegio /con la frente bien alta... /En medio del silencio, /oficial, yo le pido/ no encandile mi rostro /lo que usted está haciendo: /Discriminación. 
bién y desde casi una década, es el nombre de una lucha colectiva: mostración provocadora que los jóvenes hacen de sus gorras, capaz de tornar a un estigma, en emblema (Reguillo, 2007).

Es así como en la creación colectiva de significaciones contra-hegemónicas, la práctica política de los jóvenes de sectores populares cordobeses se anuda con la reivindicación de su cultura:

Vinimos al centro a demostrar que esta es nuestra cultura, la cultura de los jóvenes, la cultura que aguanta, que resiste que la verdugueen ${ }^{25}$, que delincuentes le choreen ${ }^{26}$; venimos acá a demostrar lo que somos. Octava Marcha de la Gorra: ¡esto es un embrollo ${ }^{27}$, esto! Toda esta gente acá, celebrando nuestra cultura (Discurso público pronunciado durante la Octava Marcha por un miembro del Colectivo, 20/11/2014).

(...) Estos somos los peligrosos, los merodeadores, los que hacemos escándalo en la vía pública cuando estamos en la esquina del barrio tomando una gaseosa. No puede ser que vayan presos los pibes ${ }^{28}$ por estar en la esquina de su barrio, compartiendo divirtiéndose, habitando el espacio público de Córdoba. Las calles son nuestras, el 20 de Noviembre y todos los días del año, queremos que sean nuestras. ¡Abajo el Código de Faltas! (Discurso público pronunciado durante la Octava Marcha por un miembro del Colectivo, 20/11/2014, 20/11/2014).

25 Categoría local que remite a castigos físicos, abuso, coacción.

26 Categoría local que significa robar.

27 En el año 2014, la Octava edición de la Marcha asumió como consigna principal "Más vale gorras embrollando que la policía matando". La palabra embrollo es una categoría de uso local, particularmente dentro de la comunidad discursiva juvenil popular cordobesa. Remite a múltiples sentidos asociados. A veces a "tramar", es decir, un hacer colectivo que permite el desarrollo de deseos y gustos compartidos y que, ocasionalmente, recibe reprobación del mundo adulto por estar reñidos con normas morales. En este sentido se lo utiliza para designar a las actividades recreativas y culturales previas a la Marcha, que desde el año 2014 reciben la denominación "Alto embrollo!" y se realizan con el objeto de dar visibilidad a las producciones culturales que surgen desde los barrios, como los talleres de poesía o comunicación, el hip hop, los grafitis. En el contexto discursivo de la Marcha, el embrollo excede su significado más difundido (el de enredar o complicar algo, de acuerdo a la Real Academia Española) y se constituye como una categoría que expresa en acto la subjetivación de los jóvenes. Embrollar es hacer ruido, hacer lío de una manera festiva. A través del embrollo -colorido, lúdico y hasta provocador- los marchantes hacen ver y oír su impugnación a aquella construcción hegemónica que imagina, narra y produce al sujeto pobre como portador de peligros en potencia.

28 Categoría local que significa jóvenes. 


\section{Múltiples demandas, múltiples actores}

A medida que nos fuimos sumergiendo en el análisis de las notas de campo, de las conversaciones-en-Marcha, de las entrevistas post Marcha, en la dinámica organizativa y política del evento, comenzó a delinearse una conjetura: la experiencia-Marcha se caracteriza por su multiplicidad. Su carácter diverso y complejo, no solo se sustenta en el crecimiento exponencial de la manifestación desde sus inicios, sino en la diversidad de demandas que la misma intenta articular y, consecuentemente, de actores que pueden sentirse potencialmente convocados por ella.

Si bien podría pensarse que en su corazón contencioso insiste, marcha tras marcha, el reclamo por la "Derogación ${ }^{29}$ del Código de Faltas", ya desde su quinta edición en el año 2011, este se acompaña del enunciado imperativo "Basta de gatillo fácil ${ }^{30 "}$ ". La transformación de la política de seguridad de la Provincia de Córdoba aparece, entonces, como una demanda que la Marcha articula de manera sustancial. En términos generales y tal como ya lo hemos insinuado, podríamos decir que esta manifestación anual se levanta en contra de la vulneración sistemática por parte del Estado de los derechos de determinados sectores sociales. Estas reivindicaciones están presentes, también, en el Documento público que se elabora colectivamente y se lee al final de la Marcha:

Somos la Marcha más grande y sistemática de Córdoba, y del PAÍS, que reivindica nuestras culturas populares y repudia rotundamente este Estado policial que nos excluye, nos reprime, nos persigue, nos estigmatiza y nos mata.

29 Incluso la propia enunciación de esta demanda ha sufrido desplazamientos en su sentido, para pedir la "anulación" en vez de "derogación", lo cual remite a figuras jurídicas diferentes, que apuntan a efectos políticos y legales también diversos. Lucrecia, una de las referentes del Colectivo, lo expresa así: "siempre dijimos 'derogación', pero después dijimos:- 'che, hay organizaciones pidiendo la anulación'. Sí tenemos claro que la modificación es lo que nos interesa. Pero está la diferenciación entre la derogación y la anulación, que nos estamos dando cuenta que no es lo mismo, pero bueno, estamos ahí..." (Conversación grupal, 28/10/2014). En orden a esa dubitación, es que en este artículo retendremos la denominación "derogación", sin desconocer que actualmente existe esta discusión al interior del campo contencioso de la Marcha.

30 Forma coloquial de aludir en Argentina a causa de muertes por armas de fuego producidas por fuerzas policiales, que generalmente se presentan como una acción accidental o en el contexto de un enfrentamiento, encubriendo que se trata de asesinatos en el marco de un ejercicio abusivo de la autoridad policial. 
'(...) Exigimos: -Derogación del Código de Faltas. -Acceso a información pública sobre la cantidad real de detenciones efectuadas por el código de faltas y accionar policial. -Basta de gatillo fácil" (Documento público de la Novena Marcha).

Además, con el paso del tiempo el sentido político evidente de la Marcha se ha diversificado y complejizado en varias direcciones:

La Marcha en sí ha ido tomando tal trascendencia y magnitud, que es como que aglutina un montón de reclamos, que van más allá del mismo Código, que tiene que ver con reclamos que también están inscriptos en el marco de los Derechos Humanos (Agustín, integrante del Colectivo, conversación grupal, 27/3/2015).

Aún dentro de los afectados directos por la aplicación de la normativa, encontramos una variedad de actores que excede a los jóvenes detenidos por "portación de rostro": también las trabajadoras sexuales ${ }^{31}$, los artesanos ${ }^{32}$, los vendedores callejeros, son alcanzados por el dispositivo jurídico.

Ahora bien, cuando el orden de problematización en el que se inscribe esta demanda puntual se construye simbólicamente en términos del vasto campo de la "violación a los Derechos Humanos", entonces los límites de los reclamos que puede alojar se vuelven difusos, pudiendo entonces ser incluidos una multiplicidad de conflictos y sus afectados.

En la Séptima Marcha de la Gorra, por ejemplo, comenzaron a participar los miembros del denominado "Acampe de Malvinas Argentinas", que reclaman en contra de la instalación de una planta secadora de semillas de maíz de la empresa multinacional Monsanto, en una localidad cercana a la ciudad de Córdoba, lo que supondrá la aplicación de agroquímicos, herbicidas o pesticidas en grandes volúmenes, con el consecuente riesgo en una

31 Si bien en la Argentina la prostitución no se considera delito, al no encontrarse regulada en el diseño jurídico actual, encontramos algunas normativas que terminan haciéndola objeto de sanciones en la práctica, cuando por ejemplo esta actividad se hace explícita en la vía pública. En el ámbito de la Provincia de Córdoba, esta situación se encuentra tipificada como figura en el Código, en su artículo 45, siendo su aplicación la principal causa de detenciones arbitrarias y maltratos hacia las trabajadoras sexuales, por parte de la Policía.

32 Da cuenta de ello la siguiente intervención: "Somos otra víctima más de este Código, porque te ven rastas, porque te ven artesano... vamos a apoyar la Marcha, en la feria pasa mucha gente, a nosotros nos aplican el Código... no sólo viene el municipal, viene el policía y te roban las cosas" (Registro de reunión, Séptima Marcha, realizado por Andrea, integrante del equipo de investigación. 1/11/2013). 
zona urbanizada. Enseguida, se produce una agregación de demandas vinculadas al rechazo al llamado "modelo agroindustrial", en términos de "oposición a esta poderosa empresa transnacional que promociona sus productos transgénicos sin tener en cuenta los costos sociales y ambientales asociados" (Zacune, 2012, p. 2). Al respecto, uno de los integrantes del Colectivo expresa que esto permite:

Mostrar que son problemas de la misma política sostenida por los gobiernos de los distintos niveles. Está bueno visibilizar que es parte de la misma política de expulsión. Así como expulsan a los pibes de los barrios, expulsan a los campesinos del campo (Registro de reunión, Séptima Marcha, realizado por Andrea, integrante del equipo de investigación. 1/11/2013).

De este modo, la Marcha se torna escenario para la expresión de numerosas y heterogéneas demandas, que parecen quedar incluidas en un "nosotros" capaz de agenciar(se) en múltiples territorios de disputa:

Somos nosotros y nosotras. Somos los pibes y las pibas de los barrios, de los bailes y las canchas, de las cárceles de todo el país. Somos las trabajadoras y los trabajadores que luchamos todos los días por la dignidad; que soportamos la explotación, el salario bajo y la represión de la cana ${ }^{33}$ cuando protestamos. Somos las trabajadoras sexuales históricamente criminalizadas, asesinadas en la clandestinidad, golpeadas y perseguidas por los gobiernos que son cómplices de los responsables de la trata y el proxenetismo. Somos las y los estudiantes que luchamos por la educación pública, gratuita, de calidad y laica. Somos artesanos y artesanas, $\operatorname{carreros}^{34}$, somos quienes impedimos que Monsanto se instale en Córdoba (...).Somos las radios abiertas y comunitarias, los medios alternativos. Somos las murgas y los movimientos culturales (Documento público de la Novena Marcha de la Gorra, 18/11/2015).

Pero más allá de esta compleja diversidad, podría identificarse un "núcleo duro" de reclamos (Chaboux y Monsó, 2015), que permanecerían sin discusión respecto de su potencial de representación de la acción colectiva. Los mismos, como ya lo adelantamos, tienen que ver con el abuso policial en todas sus formas y consecuencias, y se enlazan con un fuerte cuestionamiento

33 Categoría local que significa policía.

34 Categoría local referida a aquellos que utilizando carros se ganan la vida practicando el "cirujeo", un trabajo informal que consiste en la recolección, reciclado y venta de materiales -generalmente cartón- que obtienen de la vía pública. 
hacia la política de seguridad del Gobierno de la Provincia de Córdoba. Esto nos lleva a reconocer el sofisticado trabajo de elaboración política del cual la Marcha es escenario, porque implica inscribir la problemática más allá de una mera disputa jurídica o de una disposición vengativa hacia la policía.

Ahora bien, la elasticidad con la cual se definen los límites de este núcleo central de la demanda es, en sí, una cuestión que los jóvenes convocados por la Marcha politizan: el que quede circunscripta a un problema provincial o que se la construya como nacional, suele ser el eje de intensas disputas al interior de la organización de la Marcha. Si el motor interno de una movilización lo constituye, en parte, la interpelación directa a los responsables políticos (Filleule y Tartakowski, 2015), entonces su identificación determinan la orientación ideológico-partidaria de la Marcha.

Las interpretaciones por las cuales el reclamo central de la acción colectiva forma parte de una política de seguridad del Estado provincial, desembocan en la responsabilización institucional y política del entonces gobernador cordobés José Manuel De la Sota. Este ha sido un opositor declarado a la administración nacional que tuvo de manera sucesiva a Néstor Kirchner y Cristina Fernández de Kirchner como presidentes de la Argentina desde el año $2003^{35}$. En este contexto, el énfasis que se imprima en torno a la identificación de los antagonistas de la acción colectiva en sus declaraciones públicas es un asunto intensamente disputado y de difícil resolución, ya que coexisten en un mismo espacio agrupaciones políticamente antagónicas. Por ejemplo en los debates que conlleva la escritura del Documento público, se observa reiteradamente cómo desde la militancia kirchnerista, se intenta encapsular el problema en la dinámica política-institucional de la Provincia de Córdoba (y plantean que el interlocutor de la Marcha debe ser sólo el gobierno provincial y sus políticas de seguridad y de desarrollo social), mientras que los opositores al gobierno nacional -generalmente pertenecientes a partidos de izquierda (organizaciones trotskistas, anarquistas, y otros sectores anti kirchneristas)- pretenden extender las fronteras del conflicto para responsabilizar en un mismo movimiento al gobierno provincial y nacional.

(Se lee el borrador con los avances de lo escrito como Documento de cierre, por la Comisión correspondiente, en la sesión Plenaria). Militante de agru-

35 Cabe aclarar que este escenario es previo a noviembre de 2015, cuando el Frente Cambiemos gana las elecciones presidenciales en Argentina. 
pación de izquierda: -"hay que interpelar al Secretario de Derechos Humanos... hay que ir a... no digo a pelear, pero si a interpelar". Militante de agrupación kirchnerista: -“¿estamos hablando de Nación? ¿Se marca bien toda la coyuntura actual, la renuncia de Paredes ${ }^{36}$, etc.?" Militante de agrupación de izquierda: -“A mí me parece largo, hay mucha descripción sin responsabilizar a alguien. Pincharía más a alguien. Se entiende que estamos re-mal, pero yo les pegaría más a los responsables de que estemos así. ¿Quiénes son los responsables? Porque eso no habíamos hablado... se habla de la Policía, de la Sota..." Militante de agrupación kirchnerista: -"Son tres los culpables: la sociedad, De la Sota, la Policía..." Militante de agrupación de izquierda: -"hay que discutir el tema de la lucha de clases, no sé si este espacio está dispuesto a tolerarlo, porque es diverso... A nuestro criterio, esto también lo sostiene el Gobierno Nacional, pero este debate va a generar rispideces." Integrante Mesa Organizativa: -"sí, por eso, intentamos ser lo más inclusivos... Haciendo mucho caso a todos los que nos pidieron. Ahora vamos a cortar, vamos a ser directos y concisos, y decir porque estamos en la Marcha. Lo digo para que haya paz... Para que no se enojen." (Registro de Reunión Plenaria de la Séptima Marcha, realizado por Andrea, integrante del colectivo investigador, 7/11/2013).

Militante de la Tendencia Obrera Revolucionaria: "Que la bandera no sea solo la derogación del Código sino en contra de todo el aparato represivo provincial. (...). La situación de represión y recrudecimiento policial está presente a nivel nacional (...). Exigir el Fuera Berni ${ }^{37 "}$ (Registro de Reunión Plenaria, realizado por Macarena, integrante del equipo de investigación, 12/09/2014).

En el campo de estudios de la acción colectiva, la cuestión de la definición de la demanda es central, en la medida en que opera en interconexión con la necesaria problematización acerca del agenciamiento del reclamo. En este marco, la pregunta: ¿quién demanda qué en la Marcha de la Gorra?, remite de modo inmediato a un interrogante que recorre nuestro trabajo investigativo insistentemente: ¿cuál es la relación entre los jóvenes de sectores populares ${ }^{38}$ y esta acción de protesta? Aunque la respuesta parece

36 El ex Jefe de Policía del Gobierno De la Sota, renuncia a su cargo por sospechas vinculadas a lo que luego se denominó "Causa de los narco-policías".

37 Secretario de Seguridad de la República Argentina, hasta diciembre de 2015.

38 Más allá de una definición exhaustiva, lo que queremos hacer notar con el uso del adjetivo popular es que se trata de jóvenes que además de contar con escasos capitales materiales que los ubican en una situación de pobreza, están identificados con un tipo de cultura deslegitimada desde lo hegemónico. 
obvia, es conveniente desnaturalizar toda conexión automática que pudiera establecerse, porque la cuestión está lejos de ser sencilla. Al respecto, podemos identificar un primer pliegue de interrogación: ¿ser víctima directa de la aplicación del Código de Faltas y sentirse interpelado por la convocatoria de la Marcha de la Gorra, son equivalentes? y aún, otro pliegue más: ¿sentirse convocado por esta acción de protesta se traduce de modo necesario en participar en ella? y, finalmente: ¿sólo deberían marchar los afectados directos, es decir, los que sufren detenciones arbitrarias?

Es evidente que son los jóvenes de sectores populares los que masivamente y cotidianamente resultan perseguidos por la Policía provincial, en aplicación del Código ${ }^{39}$, aunque esto no se exprese de manera cuantitativa en la composición de la Marcha. Como ya lo explicitamos, su convocatoria interpela a un amplio arco de juventudes cordobesas que no pueden caracterizarse predominantemente como de extracción popular, sino que son más bien de sectores sociales medios que poseen determinados recursos culturales:

Por ahí uno ve la marcha y ve los videos que salen después, desde la centralidad de la organización de la marcha o el tipo de intervenciones que se hacen o las mismas agrupaciones que participamos y ves mayor cantidad o mayor representación de un sector más clase media, universitaria, progresista (Noelia, militante política, en entrevista post-Marcha, entrevistada por Macarena, integrante del equipo, 20/4/15).

Aunque por tratarse de una acción multitudinaria no sistematizable, resulta imposible establecer con precisión numérica de qué modo cada una de estas organizaciones aporta a las columnas que marchan, lo que sí se puede afirmar es que las agrupaciones estudiantiles, así como las fracciones juveniles de los Partidos políticos, son las más numerosas a simple vista.

En este caso la aclaración es pertinente de modo especial, ya que la Marcha de la gorra es ocasión para articular demandas referidas a una conflictividad social que no se limita a desigualdades económicas, sino que incluye a las que resultan de la subvaloración de una cultura, tal como se desarrolló en la sección anterior. El problema del "reconocimiento" (Honneth, 2011), referido al campo popular en clave juvenil es, sin dudas, un componente central de la problemática que origina la Marcha.

39 Si bien la normativa no hace alusión en forma directa a la figura de los jóvenes como contraventores, se sabe que los detenidos a instancias de su aplicación lo son en su mayoría. Estos datos se desprenden de uno de los pocos Informes públicos emitidos por la Policía provincial, a instancias de un pedido de legisladores y expertos cordobeses realizado en 2010. 
Sin embargo, es necesario enfatizar que, desde la perspectiva aquí asumida, el señalamiento de la composición social predominante de esta acción colectiva no constituye de modo alguno argumento para impugnar su legitimidad política.

No solo no deslegitima el potencial de protesta de la Marcha, sino que, por el contrario, se lo restituye, en tanto puede pensarse como un analizador del propio reclamo. Que los jóvenes populares no vayan masivamente a la Marcha, no debería interpretarse rápidamente como indicador de descompromiso o apatía. Tampoco como falta de representatividad de la acción de protesta respecto del sentir de sus afectados. Más bien pone en evidencia la efectividad de los procesos de amedrentamiento que la persecución cotidiana ha inscripto en sus subjetividades. Si marchar implica hacerse visibles en el espacio público donde se orquesta la propia persecución, resulta muy pertinente la siguiente lectura que hace un joven universitario:

Yo creo que hoy (...) faltaron mucho de estos chicos que son los verdaderamente detenidos y hostigados por este Código de faltas (...), creo que eso también es una forma de que el miedo esté ejerciéndose de manera efectiva por la policía (Registro de conversación-en-Marcha, realizado por Andrea, integrante del colectivo investigador, 20/11/2012).

El acoso policial que sufren los jóvenes de sectores populares no se suspende el día de la Marcha; por el contrario, parece incluso intensificarse. Dan prueba de ello algunas circunstancias que forman parte de nuestros registros etnográficos. Por ejemplo, el inicio de sus dos últimas ediciones se retrasó por detenciones arbitrarias realizadas por policías a ómnibus que trasladaban manifestantes que intentaban confluir desde distintos puntos de la ciudad de Córdoba y del interior provincial. En 2014, por caso, se demoraron a jóvenes que venían desde la localidad cercana, Juárez Celman, lo cual es comunicado a través de los altoparlantes de la Marcha, con la advertencia "No vamos a salir hasta que no se resuelva" y el aviso de que ya estaban yendo al lugar abogados que reclamarían por la liberación de los detenidos. Cuando por fin la Marcha emprendió su avance, este hecho fue interpretado por sus oradores de esta manera:

Como no quieren que marchemos y nos tienen miedo, hoy los compañeros están sufriendo la detención. Sufrimos la detención de dos colectivos. (...) Hoy De la Sota sabe que una vez más salimos a decirle basta a las calles; 
una vez más estamos dispuestos a seguir luchando por nuestras ideas, por nuestras convicciones; porque hoy, más que nunca, estamos convencidos que la policía de la provincia de Córdoba lo único que genera es violencia, es maltrato, es inseguridad. De la Sota, ¿de qué seguridad nos estás hablando? (Discurso público, pronunciado por joven del colectivo organizador de la Marcha, durante la Octava Marcha de la Gorra, 20/11/2014).

Las estrategias que desde la mesa organizadora de la Marcha se diseñan y adoptan para proteger a los marchantes, constituyen un argumento más que da cuenta del recrudecimiento de la persecución policial que ese día sufren los jóvenes alcanzados por la aplicación del Código de Faltas:

Surge como propuesta que cada agrupación que lleva pibes a la Marcha, tenga una lista con sus nombres y que en caso de efectuarse alguna detención o algo similar, se dé aviso de inmediato, para poner en acción al equipo de abogados y demás procedimientos que usualmente activa el Colectivo organizador de la manifestación (Registro de reunión organizativa previa a la Octava Marcha de la Gorra, realizado por Macarena, miembro del colectivo de investigación, 14/11/2014).

Otro criterio indicador de la preocupación que se tiene respecto de la propia seguridad de los jóvenes, que desde los barrios pobres de la ciudad confluyen al centro para participar de la Marcha, tiene que ver con el horario de finalización de la misma. En nuestros registros etnográficos de las reuniones organizativas previas, se intensifican a lo largo de los años, las menciones referidas a los ajustes necesarios para evitar que la movilización termine avanzada la noche, porque el transitar por la vía pública a esas horas facilita el hostigamiento policial hacia los jóvenes cuando regresan a sus barrios desde el centro de la ciudad.

Estas evidencias recogidas en nuestro trabajo de campo permiten dar fundamento al argumento por el cual sostenemos que las experiencias de acoso policial que los jóvenes directamente afectados por el Código de faltas, tanto en su vida cotidiana como en la propia ocasión de la Marcha, operan como una amenaza real que obtura las posibilidades de participar de la misma en las calles de Córdoba.

En este contexto que acabamos de explicitar, instalar la pregunta por “¿quiénes son los que marchan?”, implica diferenciar el reconocimiento de un hecho objetivo, de los usos políticos que ciertos sectores interesados en desautorizar la representatividad de la Marcha pudieran hacer, para invali- 
darla en su potencial de demanda. En este sentido, uno de los integrantes del Colectivo refiere: "sale una nota (periodística) donde, justamente, sale como que en realidad son todos universitarios... y también como que hay una cosa con que no está bien distribuida la voz en la Marcha" (Santiago, conversación grupal, 27/3/2015).

En el trabajo de campo, se pueden observar recurrencias respecto del componente "universitario" y "militante" de la Marcha: "a mí nunca me detuvieron (...) acá hay mucho universitario, mucho militante" (Registro de conversación-en-Marcha con joven militante de Partido político, realizado por Andrea, integrante del Colectivo investigador, 20/11/2012). Son los propios jóvenes marchantes, entonces, los que tematizan la cuestión: ¿habría algo así como un orden legitimador que justificara el derecho a marchar? Siendo así, ¿en qué criterios se apoyaría?

Estas inquietudes recrean un viejo tópico de discusión, que incluso habilitó la emergencia del que en su momento fuera un campo político nuevo: el de los movimientos sociales. La referencia remite a la superación de la cuestión de la clase como articulador de las demandas sociales, frente al cual nuestro posicionamiento es que el núcleo de la cuestión social que la Marcha pone en escena se ubica, en todo caso, en una forma combinada de injusticias derivadas de la distribución de los recursos materiales y serios déficit en el reconocimiento (Fraser, 1997) de la cultura popular juvenil como legítima. Entonces, el no padecer de manera cotidiana situaciones de hostigamiento y persecución policial, no implica una incapacidad esencial para comprender el dolor del otro y afectarse por vivir bajo una situación de vulneración de derechos.

En síntesis, identificarse electivamente con el padecimiento de los sectores populares, no inhibe a los jóvenes de otras procedencias sociales en su capacidad de agencia política. Sostener lo contrario, nos llevaría por el resbaladizo camino de privatizar el derecho a protestar y marchar.

En otro pliegue más que puede ofrecer esta cuestión, Lucrecia, una de las integrantes del Colectivo se pregunta:

¿Cuánto más le vas a pedir a un pibe? Los cagan a palos, y encima vos le pedís que hagan algo... ¿cuánto más? Me parece que la clave es que a esa gente que no le pasa, pueda sentir algo de toda esa violencia que se vive en las comunidades todo el tiempo... (Conversación grupal, 28/10/2014).

Más allá del interés teórico y político que estas reflexiones puedan albergar, es necesario insistir que en un sentido de reivindicación histórica, la 
identidad de la Marcha se encuentra sintetizada en su nombre, en tanto símbolo de una cultura despreciada y perseguida desde lo hegemónico. Como recuerda Lucrecia, integrante del Colectivo:

Cuando empezamos estaba muy fuertemente vinculado a la necesidad de que Córdoba adhiera a la Ley Nacional $26.061^{40}$, que por eso la movilización empezó siendo de los niños. Y los jóvenes fueron ahí a apoyar y cobraron una identidad propia con la gorra. Y tenía que ver con eso, dar visibilidad a algo que las organizaciones venían trabajando en sus barrios, que venía siendo una lucha de mucho tiempo y había que sacarlo a la calle (Conversación grupal, 28/10/2014).

\section{Palabras finales}

La Marcha de la Gorra es una manifestación anual que demanda, en términos generales, la transformación de la política de seguridad de la Provincia de Córdoba, y, particularmente, la derogación de su herramienta legal aunque inconstitucional y violatoria de derechos humanos- más visitada: el Código de Faltas.

Experiencia de politización para casi 20000 jóvenes cordobeses en su última edición en 2015, la Marcha es comparable a un manantial inagotable de texturas, colores, sonidos, olores, sensaciones que exigen la capacidad de los sentidos para registrarla y más aún, para producir análisis al respecto.

Se trata de una multiplicidad de multiplicidades: de demandas, actores, recursos expresivos, colores y sonidos... Caleidoscopio de devenires, sentidos, intensidades, de instantes, encuentros y velocidades. Hay tantas marchas en una sola marcha que podríamos preguntarnos si esta protesta podría ser designada a través de significantes que indicaran lo "uno".

La multiplicidad designa el nombre de una huida: la de la referencia a la identidad, al pensamiento unitario que sólo puede explicar en un único sentido. En este caso, esto implica sostener como hipótesis de trabajo que aquello que designamos con el significante "Marcha", aloja en tensión planos que pudieran pensarse como contradictorios pero que, desde la posición que estamos asumiendo, le dan justamente una cualidad enriquecida, imprevisi-

40 Ley de Protección Integral de los Derechos de las Niñas, Niños y Adolescentes, sancionada por el Congreso de la Nación Argentina en 2005. 
ble, abierta a los interrogantes. En síntesis, implica no renegar de la diversidad de modos de sentirse interpelado por las consignas de la Marcha y de participar en ella, sino de pensarla como una oportunidad para la construcción política colectiva de los jóvenes cordobeses, no exenta de confrontaciones que producen malestares y dolores.

Uno de los propósitos de este trabajo ha sido aportar una lectura sobre la potencialidad política de la Marcha. En esa dirección identificamos como central la producción colectiva y democrática de representaciones sociales que instituyen formas alternativas de pensar, significar y sentir el ser un joven de sector popular en Córdoba, lo cual se anuda a la reivindicación de su propia cultura. Esto implica la impugnación de las imágenes y creencias que circulan hegemónicamente sobre ellos, cargadas de valoraciones altamente negativas que se expresan en cadenas significantes que enlazan de manera unívoca el ser pobre con el ser delincuente.

Si tenemos en cuenta que estas construcciones dominantes acerca de las juventudes populares como responsables de la inseguridad justifican los procesos de persecución policial -que a veces son el preludio de su propia muerte-, resulta evidente que se trata de un trabajo eminentemente político. Esta afirmación puede ser desplegada al menos en dos sentidos interconectados. Por una parte, la Marcha se constituye en una experiencia de subjetivación política en la medida en que genera condiciones para restituir el reconocimiento al estilo de vida de los jóvenes populares y de ahí, posibilita el desarrollo de procesos de agenciamiento necesario para sostener la lucha. Por otra, los procesos de sociabilidad que se desarrollan de manera específica en las reuniones previas de organización suponen la construcción polifónica de voces que se articulan, incluyendo intensas disputas simbólicas, para constituir una trama argumental por la que los propios afectados dan sentido y explican la génesis de lo que les ocurre, inscribiendo sus demandas en lógicas complejas que operan al modo de marcos de significado de la acción colectiva (Tarrow, 1997). Se trata, en síntesis, de la producción de procesos enmarcadores de la acción, lo cual habita un ejercicio de reflexividad política colectiva acerca de lo que el Estado policial cordobés está haciendo con sus vidas, al perseguirlos sistemáticamente y declararlos prescindibles ${ }^{41}$.

41 Al respecto, y solo a modo de conjetura inicial que requiere de profundizaciones en el futuro, es posible enunciar que este posicionamiento de los jóvenes cordobeses que militan en la Marcha de la Gorra, encarna un matiz de diferencia respecto de algunas afirmaciones de la literatura sobre la 
Si bien podría sostenerse que todos los promotores de la Marcha se nuclean contra el Código de Faltas, los horizontes políticos de esta articulación varían, dadas las posiciones encontradas de los participantes que son militantes de organizaciones políticas. Para explicar esto, hemos situado a la Marcha en el contexto político nacional y provincial de los últimos años en Argentina, y en las disputas concomitantes de las cuales esta acción en particular opera al modo de caja de resonancia. Esto somete a la acción colectiva a fuertes presiones, que ponen a prueba la capacidad de aquellos que la agencian para lidiar con estos intereses encontrados sin que la misma se fracture, constituyéndola en un escenario para la socialización política de jóvenes cordobeses desde hace casi diez años. En efecto: este sofisticado trabajo de articulación de posiciones diversas es ocasión para hacer experiencias de aprendizaje de competencias específicas de la gestión política, tales como dialogar, argumentar, convencer, o incluso, presionar discursivamente, en orden a incidir en la toma de decisiones colectivas. De este modo hemos ilustrado una de las características que en la actualidad asumen las prácticas de participación juvenil "basadas en métodos democráticos, participativos y horizontales" (Valenzuela Arce, 2015b, p. 19), sin por ello esencializarlas al modo de un edén alejado de todo conflicto.

Uno de los descriptores de esta multiplicidad de la Marcha que hemos identificado tiene que ver con la pregunta por quiénes se sienten convocados por ella. Al respecto hemos sostenido que se trata predominantemente de jóvenes de clase media militantes de partidos políticos o agrupaciones universitarias, al tiempo que propusimos que este hecho no deslegitima políticamente a la Marcha. Consideramos que se trata de un argumento tanto político como académico, en la medida en que supone poner en juego una posición teórica en relación a los resortes subjetivos y colectivos que activan la movilización, a saber: la comprensión radical que la naturaleza de la demanda es la politización de una injusticia social que excede a los afectados directos por la aplicación del Código de faltas, o dicho de otro modo, que no existiría posibilidad de no ser afectado frente a la violación sistemática de los derechos humanos por parte del Estado cordobés, que hemos inscrip-

militancia juvenil argentina. Así, por ejemplo, en un reciente trabajo sobre las formas de participación política de los jóvenes argentinos se expresa que no se "presentan en oposición a los gobiernos" (Valenzuela Arce, 2015b, p. 21), puesto que se considera en exclusividad su militancia kirchnerista en la última década. Sin embargo, este trabajo muestra que en igual periodo este análisis no es capaz de dar cuenta de la experiencia de la totalidad de los jóvenes argentinos. 
to en prácticas de juvenicidio. Restarle impacto político a la Marcha a partir de la relativa menor cantidad de participación de los jóvenes más castigados por el accionar policial, supone una restricción de los sentidos políticos de las acciones juveniles de protesta, a partir de su esencialización, modalidad de construcción teórica del problema que este artículo quiere justamente problematizar, a través de la categoría "multiplicidad" entendida como un operador epistémico desde el cual analizar la experiencia en cuestión.

Esta línea de discusión ingresa en la propia dinámica organizativa de la movilización, ya que aunque los esfuerzos para que la multiplicidad que la habita no se traduzca en conflictos que terminen por destruirla, su propio devenir inscripto en una especie de "destino desconocido, imprevisible, no preexistente" (Deleuze y Parnet, 1980, p. 142), nos llena de interrogantes respecto de su futuro, tensionado por la coyuntura política local y nacional de la Argentina y los modos de agenciamiento colectivo de los jóvenes que se sienten interpelados por la injusticia, más allá de todo esencialismo.

\section{Bibliografía}

Austin, John (1982). Cómo hacer cosas con palabras: palabras y acciones. Barcelona: Paidós.

Bonvillani, Andrea (2013). Cuerpos en marcha: emocionalidad política en las formas festivas de protesta juvenil. Revista Nómadas, 39. Colombia: Universidad Central.

(2015a). El Código de Faltas de la Provincia de Córdoba (Argentina) como dispositivo de poder. La construcción de la seguridad a partir de la equivalencia simbólica 'joven pobre=peligroso'. Revista Controversias y Concurrencias Latinoamericanas, 11. Buenos Aires: Asociación Latinoamericana de Sociología.

(2015b) (Ed.). Callejeando la alegría ... y también el bajón. Etnografía colectiva de la Marcha de la Gorra. Argentina: Encuentro Grupo Editor.

Chaboux, Melania Agustina y Monsó, Mauricio (2015). “Cartografiando devenires. Análisis etnográfico de la Marcha de la Gorra como espacio de acción política juvenil". Ponencia presentada en las XI Jornadas de Sociología de la UBA, Buenos Aires: Universidad de Buenos Aires. Recuperado de http://cdsa.aacademica.org/000-061/701.pdf [25 de setiembre de 2015].

Borges, Antonádia (2004). Tempo de Brasília: etnografando lugares-eventos da política. Río de Janeiro: Relume Dumará. 
Brocca, Magdalena, Morales, Susana, Plaza Schaefer, Valeria (2015). Políticas de Seguridad y Fuerza Policial. En: Observatorio de Derechos Humanos (Comp.), Segundo Informe Provincial 2014. Mirar tras los muros. Situación de los Derechos Humanos de las personas privadas de libertad en Córdoba. Córdoba: Editorial Universidad Nacional de Córdoba.

Chaves, Mariana (2005). Juventud negada y negativizada: representaciones y formaciones discursivas vigentes en la Argentina contemporánea. Última Década, 23, 9-32. Viña del Mar, Chile: Ediciones Cipda.

Crisáfulli, Lucas y León Barreto, Inés (2015). Ritos y violencia en Córdoba. Los jóvenes y el estado penal. En: Barrón, Margarita y Borioli, Gloria (Comp.) Jóvenes cordobeses: de los márgenes al empoderamiento. Reflexiones sobre política (pública). Córdoba: Editorial de la Universidad Nacional de Córdoba.

Deleuze, Gilles y Guattari, Félix (1997). Mil mesetas. Capitalismo y esquizofrenia. Valencia: Pre-Textos.

Deleuze, Gilles y Parnet, Claire (1980). Diálogos, Valencia: Pretextos.

Fillieule, Olivier y Tartakowski, Danielle (2015). La manifestación. Cuando la acción colectiva toma las calles. Argentina: Siglo XXI.

Fraser, Nancy (1997). Iustitia interrupta. Reflexiones críticas desde la posición postsocialista. Bogotá: Siglo del Hombre editores.

Honneth, Axel (2011). Reconocimiento y menosprecio. Sobre la fundamentación normativa de una teoría social. España: Katz Editores.

Kessler, Gabriel y Dimarco, Sabina (2013). Jóvenes, policía y estigmatización territorial en la periferia de Buenos Aires. Espacio Abierto, 22(2), 221-243.

Lescano, Paola (2015). La corporeidad de la letra. En: Andrea Bonvillani (Ed.), Callejeando la alegría ... y también el bajón. Etnografía colectiva de la Marcha de la Gorra. Argentina: Encuentro Grupo Editor.

Núñez, Pedro (2006). Patrullando la ciudad. Política \& Sociedad, 8, 159-189, Abril. Plaza Schaefer, Valeria y Morales, Susana (2013). Seguridad y democracia: tensiones de origen. Aportes al análisis de la política de seguridad en la provincia de Córdoba. Revista Estudios, 29. Córdoba: Universidad Nacional de Córdoba.

Reguillo, Rossana (2003). Ciudadanías juveniles en América Latina. Última Década, 19, 1-20. Viña del Mar, Chile: Ediciones Cipda.

(2007). Emergencia de culturas juveniles. Estrategias del desencanto. Buenos Aires: Norma.

Sabsay, Leticia (2011). Fronteras sexuales. Espacio urbano, cuerpos y ciudadanía. Buenos Aires: Paidós. 
Tarrow, Sidney (1997), El poder en movimiento. Los movimientos sociales, la acción colectiva y la política. Madrid: Alianza.

Valenzuela Arce, José Manuel (2015a). Remolinos de viento: juvenicidio e identidades desacreditadas. En: José Manuel Valenzuela (Coord.), Juvenicidio. Ayotzinapa y las vidas precarias en América Latina y España. México: El Colegio de la Frontera Norte, ITESO, NED Ediciones.

(2015b). Las voces de la calle... y de las redes sociales, los movimientos juveniles y el proyecto neoliberal. En: José Manuel Valenzuela Arce (Coord.), El sistema es antinosotros. Cultura, movimientos y resistencias juveniles. Barcelona: Gedisa.

Vázquez, Melina y Vommaro, Pablo (2009). Sentidos y prácticas de la política entre la juventud organizada de los barrios populares en la Argentina reciente. Cuadernos del CENDES, 70(26), 47-68.

Wacquant, Loïc (2004). Las cárceles de la miseria. Buenos Aires: Manantial.

(2010). Castigar a los pobres, el gobierno neoliberal de la inseguridad social. Barcelona: Gedisa.

Zacune, Joseph (2012). Lucha contra Monsanto: Resistencia de los movimientos de base al poder empresarial del agronegocio en la era de la 'economía verde’ y un clima cambiante. En: Vía Campesina, Amigos de la Tierra Internacional y Combat Monsanto. Recuperado de http://www.viacampesina.org/downloads/pdf/sp/Monsanto-Publication-ES-Final-Version. pdf [4 de marzo de 2013.]

\section{Documentos consultados}

Código de Faltas de la Provincia de Córdoba (2007). Texto ordenado 2007. Ley $\mathrm{N}^{\circ}$ 8431.

Fecha de recepción: 10/03/2016; fecha de aprobación: 26/05/2016 